\title{
IMPACTO DE LA GESTIÓN Y LIDERAZGO EN UNA UNIVERSIDAD PRIVADA EN EL SUR DE YUCATÁN, MÉXICO
}

\section{IMPACT OF MANAGEMENT AND LEADERSHIP AT A PRIVATE UNIVERSITY IN SOUTHERN YUCATÁN, MEXICO}

\author{
Juan Carlos Ortiz Navarro', Edith Juliana Cisneros Cohemour ${ }^{2}$
}

\section{Resumen}

El objetivo que persigue el presente trabajo de investigación es comprender el rol e impacto que tienen la gestión administrativa y el liderazgo ejercido por la directora para inculcar una filosofía institucional rica en contenido en su equipo de trabajo directo para desarrollar una cultura organizacional orientada al logro y al servicio. Para ello, se llevó a cabo un caso de estudio cualitativo, naturalista vivencial, en el que se convive de primera mano con los actores clave y con la comunidad universitaria en su ambiente natural para generar confianza entre el investigador y ellos, realizando entrevistas semiestructuradas a la directora, su tramo de control directo, así como, a los grupos de enfoque a alumnos de licenciatura de un Campus Universitario ubicado en el municipio de Tekax de Álvaro Obregón, Yucatán. Se logró descubrir que una correcta gestión administrativa sumada a un liderazgo sólido y congruente con la filosofía institucional de la Universidad, han logrado la permanencia y arraigo de la Universidad en la comunidad.
\end{abstract}

\section{Palabras clave}

Liderazgo; gestión administrativa; filosofía institucional, cultura organizacional orientada al servicio; cultura organizacional orientada al logro; Tekax de Álvaro Obregón; Yucatán.

\section{Abstract}

The objective that this investigation pursues, is to understand the role and impact that the administrative management and leadership executed by the Principal to inculcate an institutional philosophy rich in content in her near team to develop organizational culture oriented to achievement and service. This goal, gave the pretext to use a qualitative and naturalistic investigation, in which the researcher coexisted with clue actors and the university community, realizing semi-structured interviews with the Principal and her near team, as well as, a focus group to bachelor students of diverse knowledge disciplines of a University Campus located at Tekax de Alvaro Obregon, Yucatan, Mexico. Discovering that a correct administrative management with a solid, leadership, congruent with the institutional philosophy of the University had gotten the permanence of the institution in the community.

\section{Keywords}

Leadership; administrative management; institutional philosophy oriented to service; institutional philosophy oriented to achievement; Tekax de Alvaro Obregon; Yucatan.

JEL: I21 


\section{Introducción}

\section{El contexto de la educación en la Ciudad de Tekax de Álvaro Obregón}

Tekax cuyo significado maya es allá en el monte es un municipio ubicado al sur de la Ciudad de Mérida en el Estado de Yucatán, cuenta con un total 42440 habitantes, de los cuales el 49,02\% son hombres y el $50.98 \%$ son mujeres (INEGI, 2017). El caso de estudio corresponde a una universidad privada ubicada en la ciudad de Tekax de Álvaro Obregón, localizada a $91 \mathrm{~km}$ de la ciudad de Mérida, rumbo a Chetumal, Quintana Roo, tomando la desviación hacia las Grutas de Loltun (Gobierno Estatal del Estado de Yucatán, 2019a). Tekax de Álvaro Obregón tiene una altitud pro- medio de $20 \mathrm{msnm}$, la temperatura media es de $31^{\circ} \mathrm{C}$ (Gobierno Estatal del Estado de Yucatán, 2019b), cuenta con una población total de 25751 habitantes, de los cuales el $48.86 \%$ son hombres y $51.14 \%$ son mujeres; el índice de pobreza es del $54.4 \%$, con un $82 \%$ de población indígena, de los cuales el $43.83 \%$ son maya hablantes, de esta población el $1.83 \%$ no habla español, y el $39.53 \%$ de la población económicamente activa cuenta con empleo (Gobierno Estatal del Estado de Yucatán, 2019c).

La ciudad de Tekax de Álvaro Obregón es un poblado pequeño y colorido, en la entrada de la ciudad se encuentran unos arcos estilo colonial que tienen la leyenda: "La Sultana de la Sierra".

Figura 1.1. Entrada a la Ciudad de Tekax

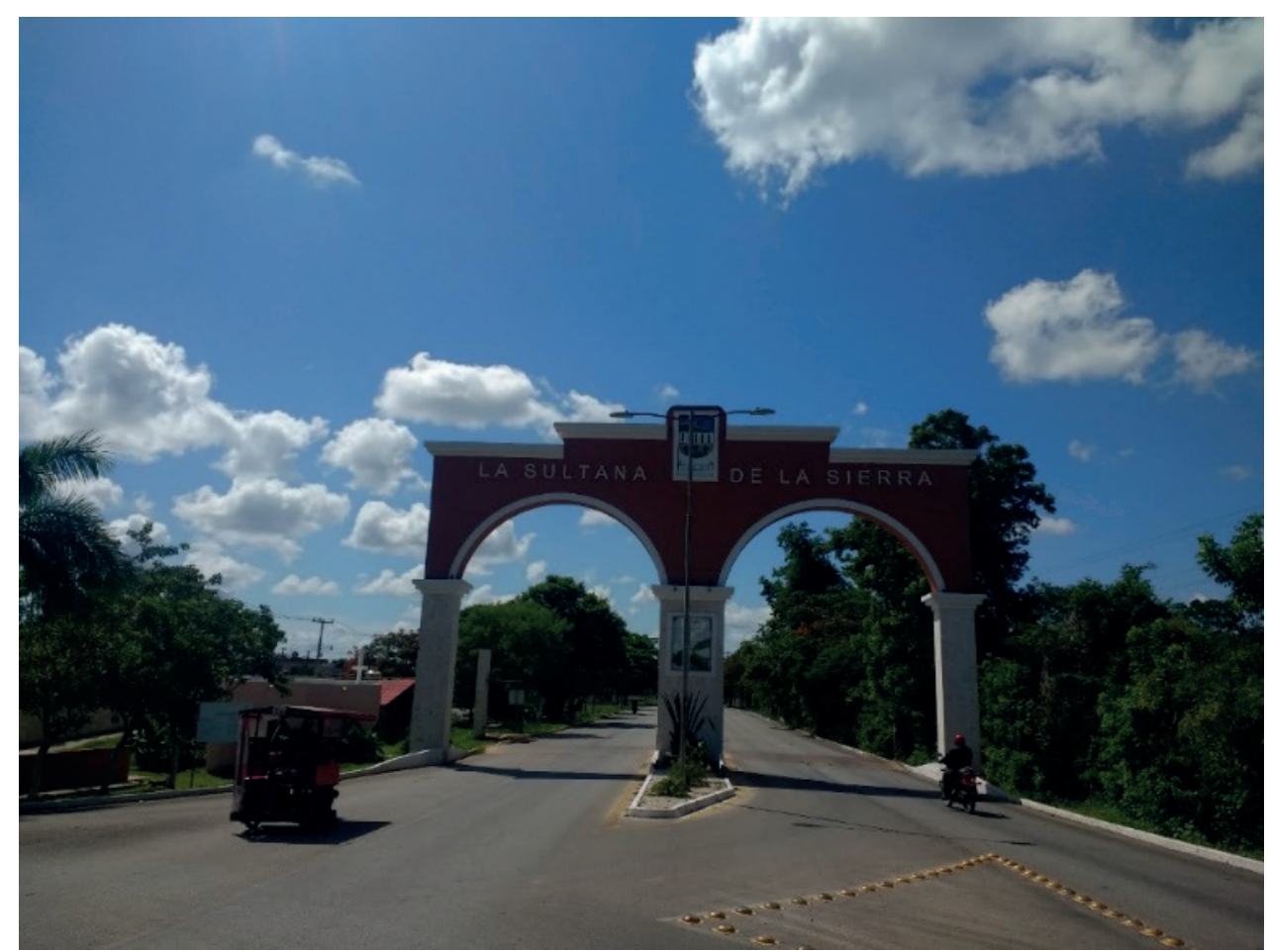

Álvaro Obregón fotografía propia.

En Tekax se pueden observar algunos pequeños cerros pertenecientes a la Sierra de Ticul, al pie de los cerros se encuentra el panteón municipal que sirve de antesala del centro de la ciudad. 
Figura 1.2. Cementerio Municipal

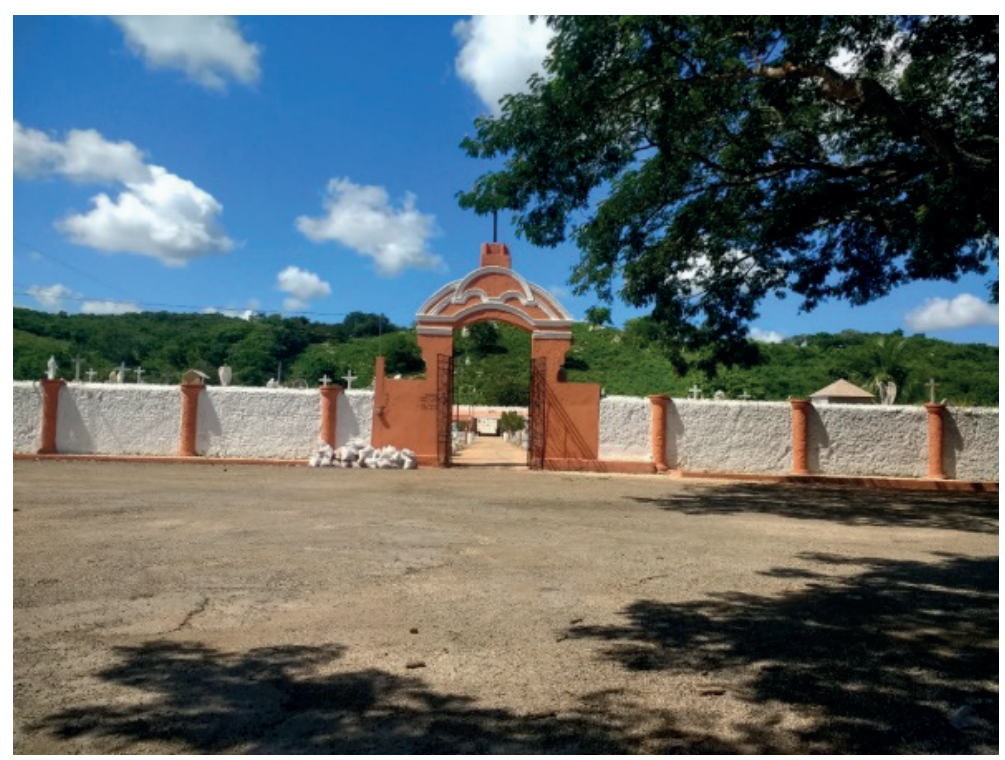

Fotografía propia.

El centro histórico de la ciudad es de arquitectura colonial, bien conservado y limpio, cuenta con un parque central estilo francés construido durante la época del Porfiriato. El parque está rodeado por la parroquia de San Juan Bautista construida entre los años 1584 y 1609 de estilo barroco; los edificios del gobierno municipal; el mercado municipal, en donde se comercializan productos de primera necesidad, materias primas, artículos religiosos, enceres domésticos y desde luego gastronomía típica de la región; escuelas y el hotel Sultán de la Sierra (Mérida de Yucatán, 2017).

Figura 1.3. Parque Central

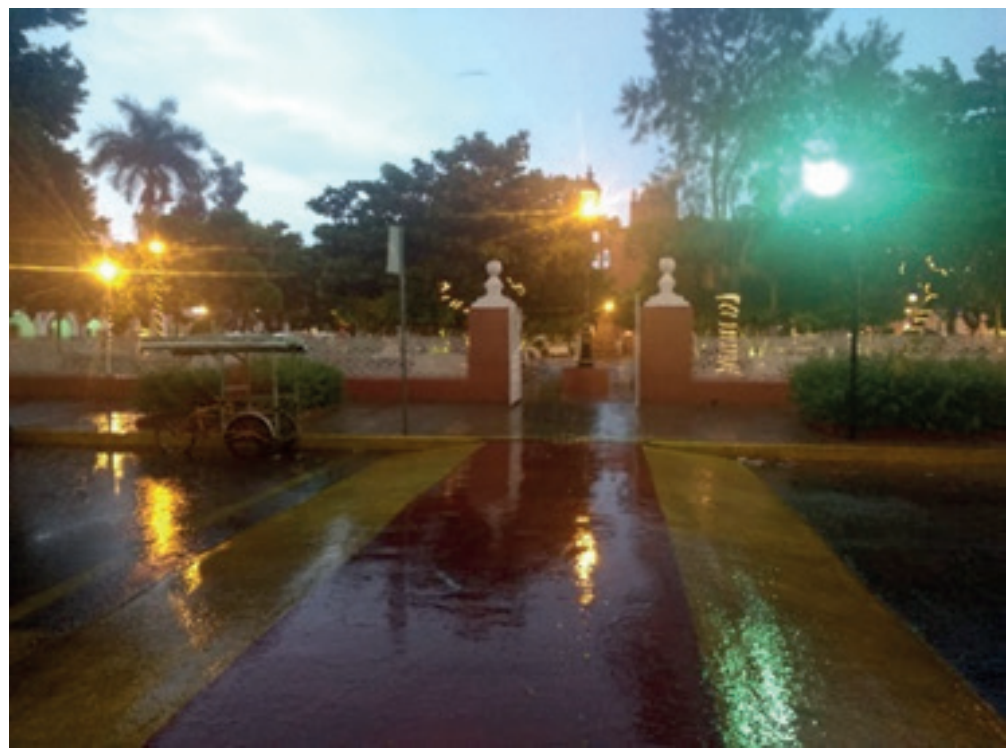

Fotografía propia. 
Figura 1.4. Parroquia de San Juan

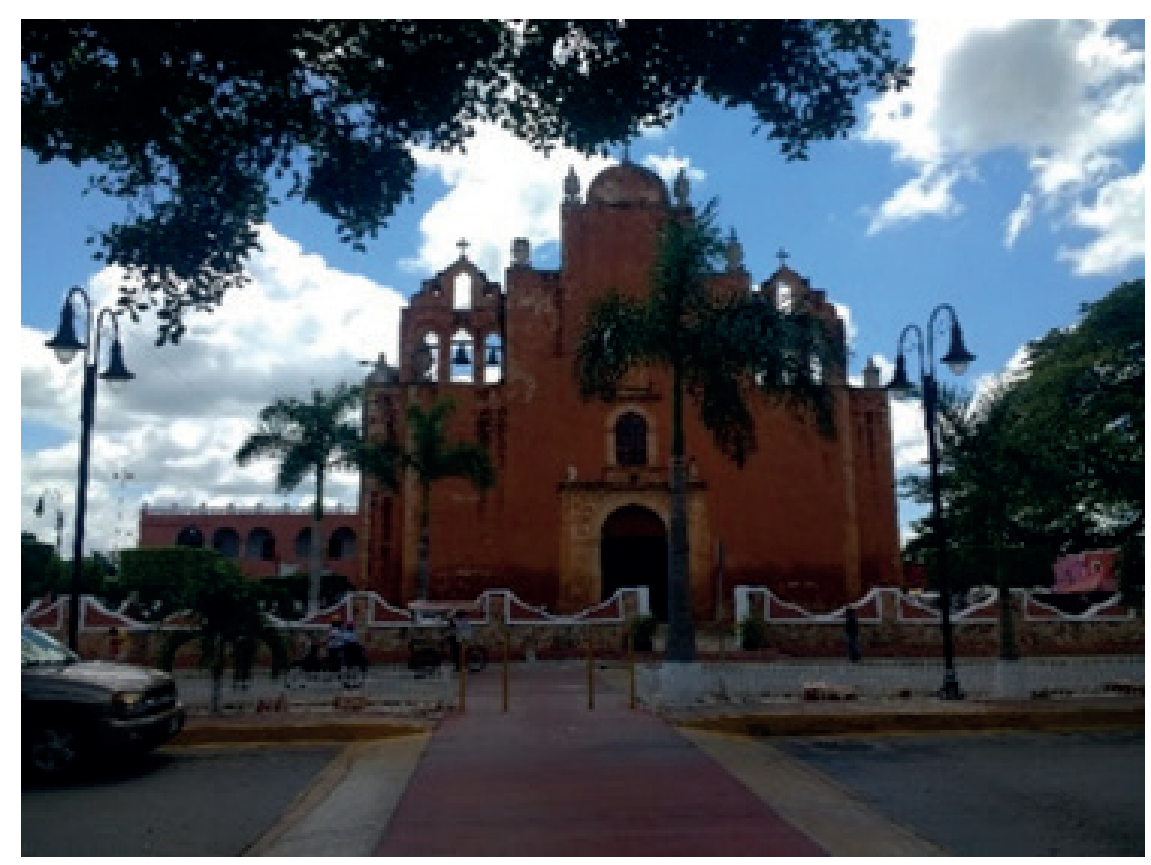

Fotografía propia.

Figura 1.5. Municipalidad

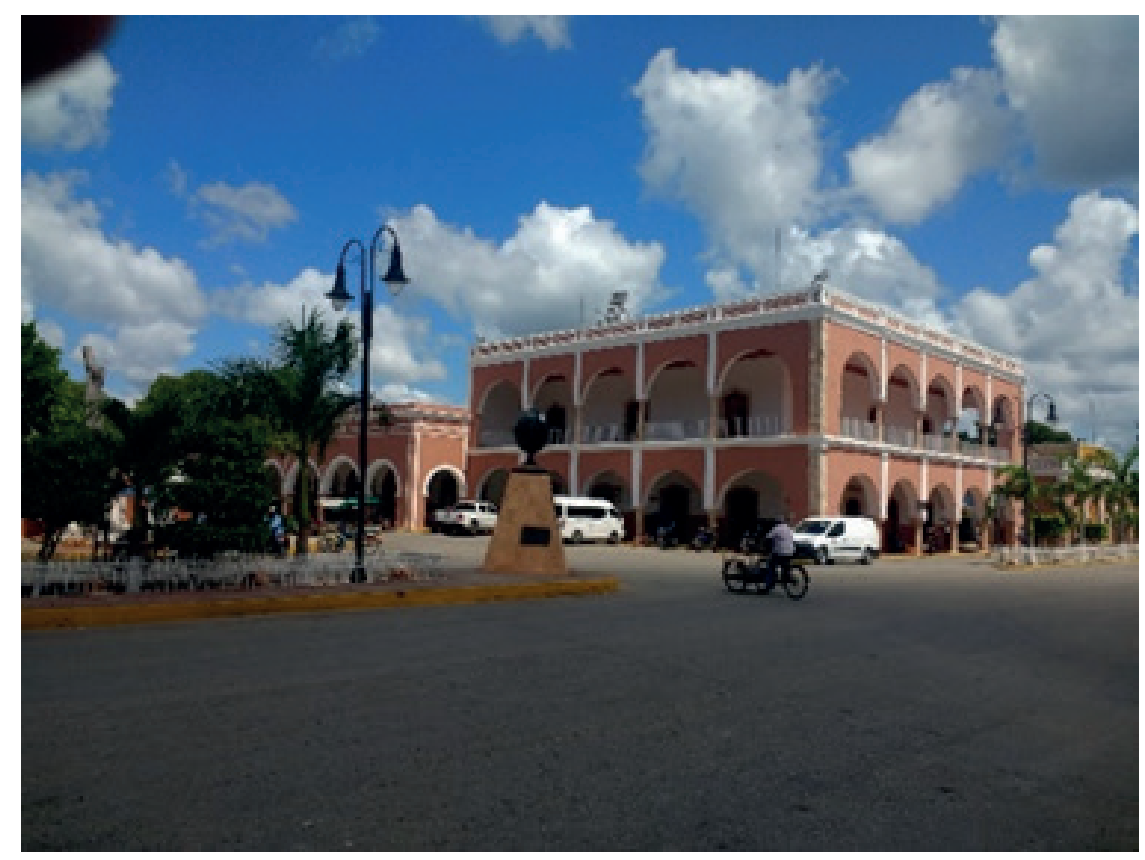

Fotografía propia. 
Figura 1.6. Hotel Sultán de la Sierra

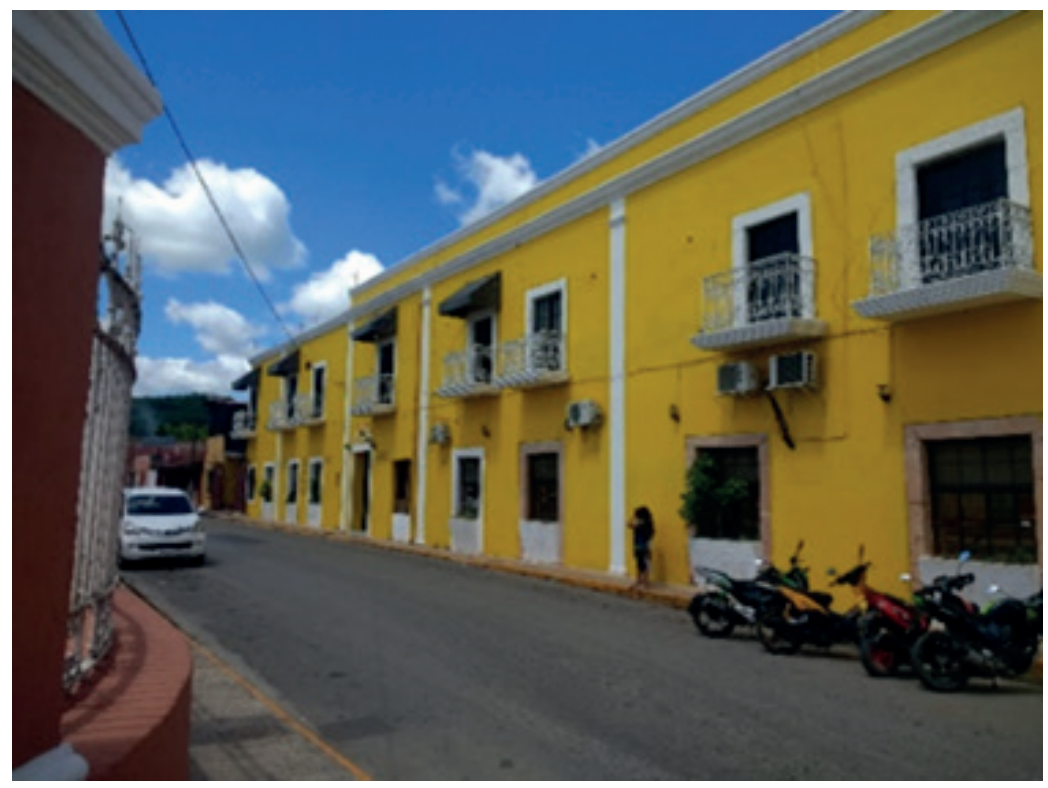

Fotografía propia.

La principal actividad económica de la ciudad es el comercio al por menor, seguida por servicios generales y profesionales; sin embargo, las principales actividades económicas de los alrededores son la agricultura y la ganadería. Una actividad que el municipio está tratando de impulsar es el turismo, ofreciendo paseos a sitios de interés como: los Bosques de Ceiba; la Ermita de San Dieguito construida en el año de 1645; las Grutas Cho- cantes que representan el Inframundo Maya y ha sido catalogada como la gruta más grande del Estado de Yucatán; haciendas que fueron testigo de la "Guerra de Castas"; las Grutas de Lol Tun; así como, las zonas arqueológicas cercanas pertenecientes a la Ruta Puc. (Promotor turístico del Municipio de Tekax, comunicación directa, 14 de noviembre de 2019)

La infraestructura educativa del municipio se muestra en la tabla 1.1 denominada:

Tabla 1.1. Dimensión del Sistema Educativo del Municipio de Tekax, Yucatán

\begin{tabular}{|c|c|c|c|c|c|c|c|c|c|}
\hline \multicolumn{10}{|c|}{ ESCUELAS } \\
\hline \multicolumn{6}{|c|}{ Educación básica } & \multirow{2}{*}{\multicolumn{2}{|c|}{$\begin{array}{c}\text { Media superior } \\
\text { Preparatoria }\end{array}$}} & \multirow{2}{*}{\multicolumn{2}{|c|}{$\begin{array}{c}\text { Superior } \\
\text { Universidades }\end{array}$}} \\
\hline \multicolumn{2}{|c|}{ Preescolar } & \multicolumn{2}{|c|}{ Primaria } & \multicolumn{2}{|c|}{ Secundaria } & & & & \\
\hline Publica & Privada & Pública & Privada & Pública & Privada & Pública & Privada & Pública & Privada \\
\hline 51 & 2 & 47 & 2 & 16 & 7 & 11 & 2 & 1 & 1 \\
\hline \multicolumn{2}{|c|}{53} & \multicolumn{2}{|c|}{49} & \multicolumn{2}{|c|}{23} & \multicolumn{2}{|c|}{13} & \multicolumn{2}{|c|}{2} \\
\hline \multicolumn{10}{|c|}{ DOCENTES } \\
\hline \multicolumn{6}{|c|}{ Educación Básica } & \multicolumn{2}{|c|}{ Media Superior } & \multicolumn{2}{|c|}{ Superior } \\
\hline \multicolumn{2}{|c|}{ Preescolar } & \multicolumn{2}{|c|}{ Primaria } & \multicolumn{2}{|c|}{ Secundaria } & \multicolumn{2}{|c|}{ Preparatoria } & \multicolumn{2}{|c|}{ Universidades } \\
\hline Publica & Privada & Pública & Privada & Pública & Privada & Pública & Privada & Pública & Privada \\
\hline N.D & N.D. & N.D. & N.D. & N.D. & N.D. & N.D. & N.D. & 105 & 50 \\
\hline \multicolumn{2}{|c|}{$y$} & \multicolumn{2}{|c|}{262} & \multicolumn{2}{|c|}{173} & \multicolumn{2}{|c|}{71} & \multicolumn{2}{|c|}{155} \\
\hline
\end{tabular}




\begin{tabular}{|c|c|c|c|c|c|c|c|c|c|}
\hline \multicolumn{10}{|c|}{ ALUMNOS } \\
\hline \multicolumn{6}{|c|}{ Educación Básica } & \multirow{2}{*}{\multicolumn{2}{|c|}{$\begin{array}{c}\text { Media Superior } \\
\text { Preparatoria }\end{array}$}} & \multirow{2}{*}{\multicolumn{2}{|c|}{$\begin{array}{c}\text { Superior } \\
\text { Universidades }\end{array}$}} \\
\hline \multicolumn{2}{|c|}{ Preescolar } & \multicolumn{2}{|c|}{ Primaria } & \multicolumn{2}{|c|}{ Secundaria } & & & & \\
\hline Publica & Privada & Pública & Privada & Pública & Privada & Pública & Privada & Pública & Privada \\
\hline N.D. & N.D. & N.D. & N.D. & N.D. & N.D. & N.D. & N.D. & 1114 & 339 \\
\hline \multicolumn{2}{|c|}{1935} & \multicolumn{2}{|c|}{5225} & \multicolumn{2}{|c|}{2542} & \multicolumn{2}{|c|}{1840} & \multicolumn{2}{|c|}{1453} \\
\hline
\end{tabular}

Fuente: elaboración propia con datos de INEE, 2019; ANUIES, 2018.

Los resultados que se han obtenido del sistema educativo de Tekax en los úl- timos cinco años se muestran en la tabla 1.2.

Tabla 1.2. Relación de alumnos egresados y titulados de las instituciones de educación superior en el Municipio de Tekax, Yucatán en los últimos cinco años

\begin{tabular}{|c|c|c|}
\hline Ciclo escolar & Alumnos egresados & Alumnos titulados \\
\hline $2013-2014$ & 233 & 194 \\
$2014-2015$ & 314 & 179 \\
$2015-2016$ & 316 & 163 \\
$2016-2017$ & 286 & 313 \\
$2017-2018$ & 175 & 129 \\
\hline
\end{tabular}

Fuente: elaboración propia con datos de ANUIES, 2014, 2015, 2016, 2017, 2018.

\section{La Universidad}

La Universidad nace en el Estado de México en el año 2000, entre los años 2000 y 2010 tiene un crecimiento sostenido con varios campus en los Estados de México e Hidalgo, como parte de dicha expansión, se decidió abrir operaciones en Mérida, Yucatán en agosto de 2010. A esta expansión se le dio identidad propia, adaptando el nombre del Campus para que fuese compatible con la identidad de los alumnos de Yucatán (Universidad Privada de la Península, 2019).

La filosofía institucional de la Universidad se manifiesta en la tabla 1.3 a continuación.

Tabla 1.3. Filosofía institucional

\begin{tabular}{|c|c|c|}
\hline Misión & Visión & Valores \\
\hline $\begin{array}{l}\text { Formar seres humanos, ciudadanos del } \\
\text { mundo que gestionen conocimiento } \\
\text { para crecer y compartir su talento con } \\
\text { el entorno. }\end{array}$ & $\begin{array}{l}\text { En el año } 2022 \text { la Universidad Privada de la Península } \\
\text { será reconocida como una organización de educación } \\
\text { superior de alto nivel, comprometida con la búsqueda } \\
\text { permanente de la excelencia en la formación de seres } \\
\text { humanos que coadyuven al desarrollo social y econó- } \\
\text { mico de su entorno. }\end{array}$ & $\begin{array}{l}\text { Honestidad } \\
\text { Respeto } \\
\text { Responsabilidad } \\
\text { Solidaridad } \\
\text { Tolerancia } \\
\text { Justicia } \\
\text { Ética }\end{array}$ \\
\hline
\end{tabular}

Fuente: elaboración propia con datos de la Universidad Privada de la Península, 2019.

La Universidad fomenta y desarrolla espacios educativos de vanguardia, para impactar positivamente en la formación de los egresados con una preparación integral en todos los niveles, estimulando el emprendimiento y encaminando su accionar hacia el reconocimiento de toda la sociedad (UPP, 2019).

La oferta educativa de la institución se muestra en la tabla 1.4 a continuación. 
Tabla 1.4. Oferta educativa

\begin{tabular}{|c|c|c|c|c|}
\hline Preparatoria & Licenciatura tradicional & Licenciatura ejecutiva & Posgrados & $\begin{array}{c}\text { Educación } \\
\text { continua }\end{array}$ \\
\hline $\begin{array}{l}\text { En ambos } \\
\text { Campus }\end{array}$ & $\begin{array}{l}\text { Administración } \\
\text { Arquitectura } \\
\text { Criminología } \\
\text { Derecho } \\
\text { Gastronomía } \\
\text { Ingeniería Industrial } \\
\text { Negocios Internacionales } \\
\text { Nutrición } \\
\text { Odontología } \\
\text { Pedagogía } \\
\text { Psicología } \\
\text { Psicopedagogía } \\
\text { Terapia Física y } \\
\text { Rehabilitación } \\
\text { Turismo }\end{array}$ & $\begin{array}{l}\text { Contabilidad } \\
\text { Derecho } \\
\text { Ingeniería en Sistemas } \\
\text { Psicopedagogía }\end{array}$ & $\begin{array}{l}\text { Doctorados: } \\
\text { Ciencias de la Educación } \\
\text { Maestrías: } \\
\text { Administración de } \\
\text { Negocios } \\
\text { Derecho Fiscal } \\
\text { Derecho Penal } \\
\text { Pedagogía } \\
\text { Psicología Organizacional } \\
\text { Especialidades: } \\
\text { Evaluación Educativa }\end{array}$ & $\begin{array}{l}\text { Diplomados: } \\
\text { Habilidades para } \\
\text { la Docencia y } \\
\text { Evaluación de los } \\
\text { Aprendizajes } \\
\text { Ortopedia Funcional } \\
\text { de los Maxilares } \\
\text { Peritaje Psicológico } \\
\text { Cursos: } \\
\text { Impacta desde Cero }\end{array}$ \\
\hline
\end{tabular}

Fuente: elaboración propia con datos de la Universidad Privada de la Península, 2019.

Para el 2012, la Universidad abrió un nuevo campus en la ciudad de Tekax, ofreciendo 11 licenciaturas y 2 posgrados

\section{El campus}

El campus se encuentra a un par de cuadras del parque central, su fachada pasa desa- percibida, a no ser por un letrero que contiene el nombre de la institución, la fachada tiene deterioro y pertenece al casco antiguo de un edificio colonial.

Figura 1.7. Propia, acceso principal de Campus Tekax

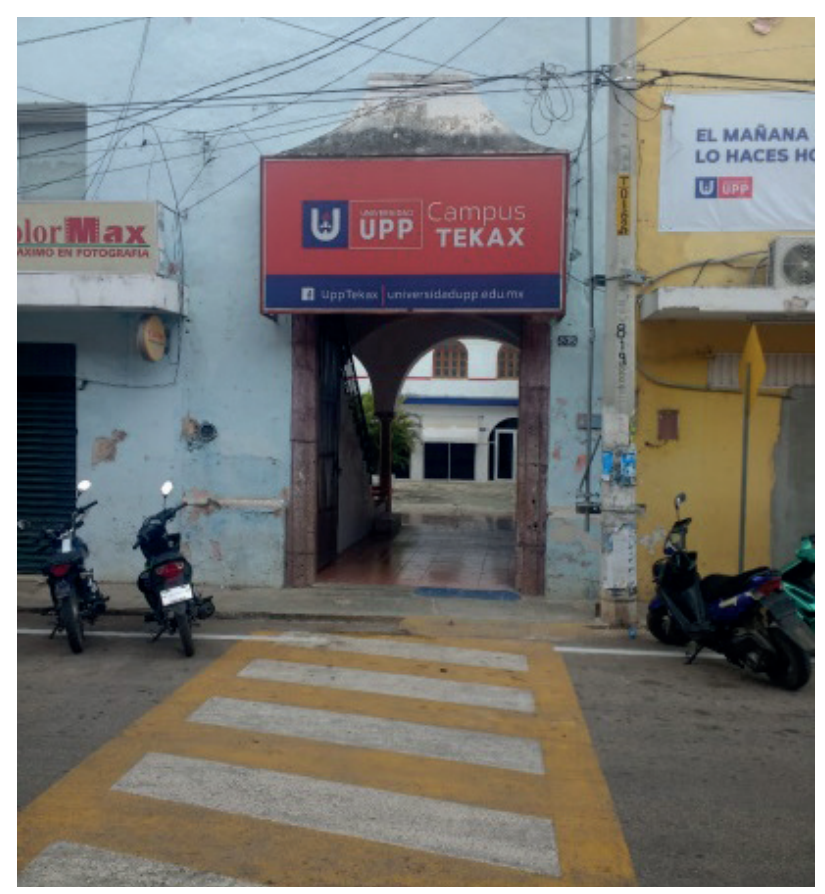


La infraestructura del consta de: 1 área de Relaciones Públicas en donde se brinda información sobre los planes de estudio a alumnos potenciales; 1 área de común en donde se encuentra la Jefatura de Servicios Escolares, la Coordinación de Servicio Social y Titulación, la Caja; 1 oficina para el personal de mantenimiento; 1 área común para las coordinaciones de Carrera; la oficina de la Dirección del Campus; 1 auditorio; 1 centro de cómputo; 1 bar y cocina para la carrera de gastronomía; 1 biblioteca; sanitarios para hombres y mujeres; 2 patios; 1 cafetería, 1 anexo al frente del Campus en dónde se estableció la clínica para prácticas de los alumnos de odontología, 1 laboratorio para la carrera de enfermería y 15 aulas con equipo multimedia con capacidad para 20 alumnos por aula.

Figura 1.8. Propia, lobby

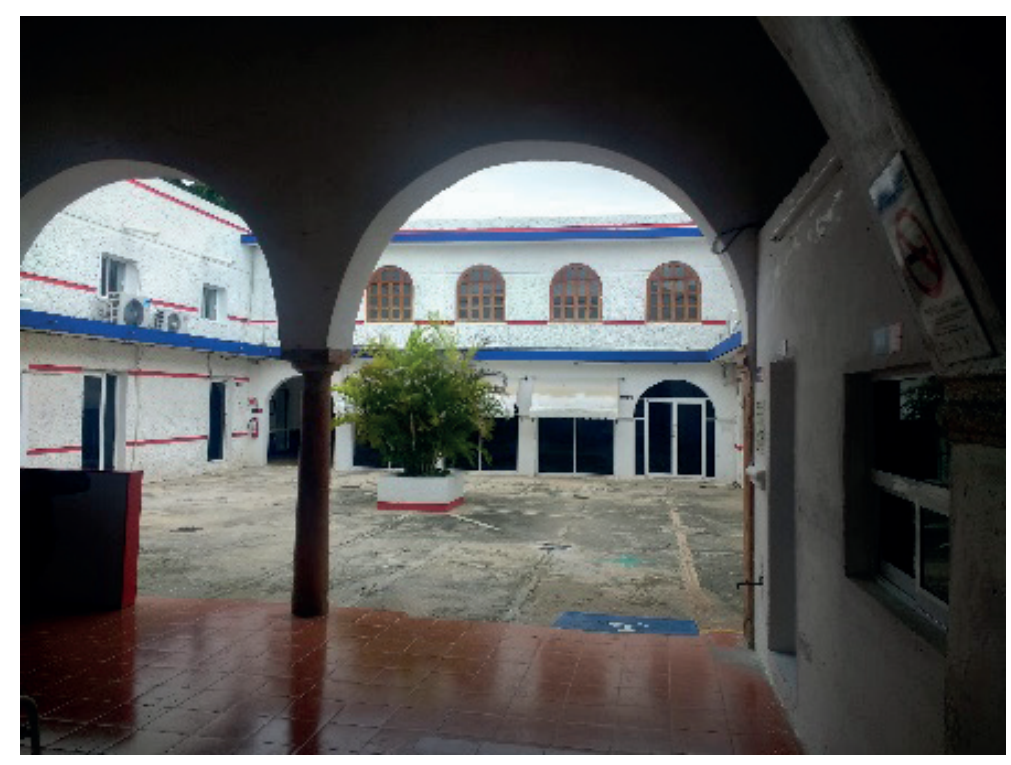

Figura 1.9. Propia, patio principal

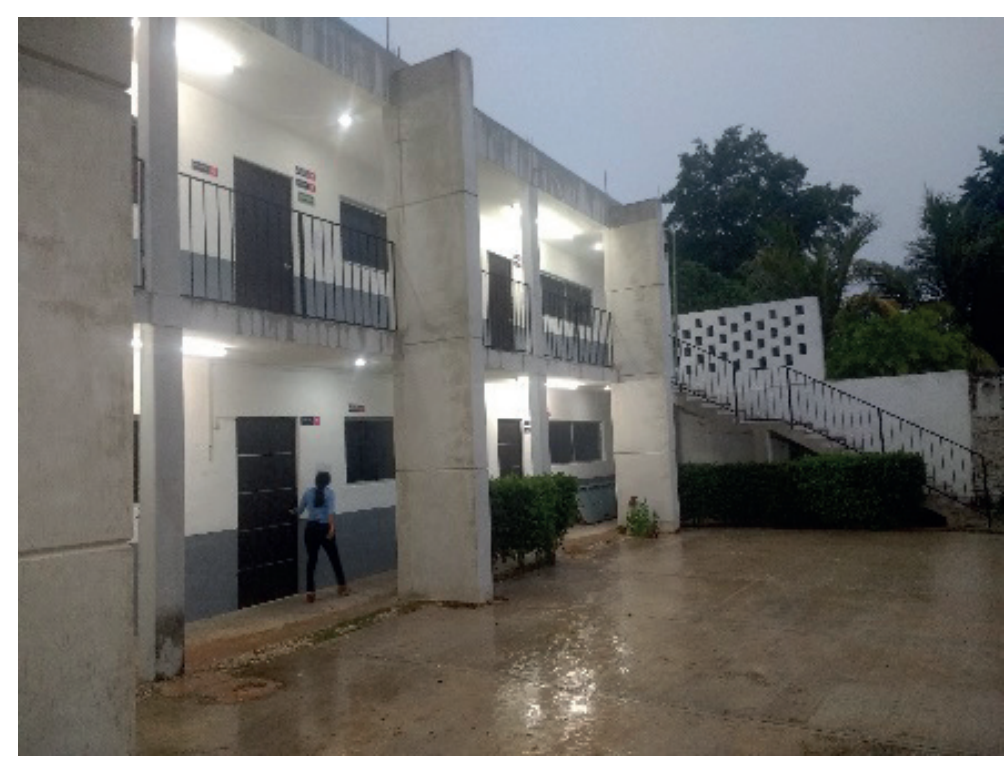


Figura 1.10. Propia, aula licenciatura

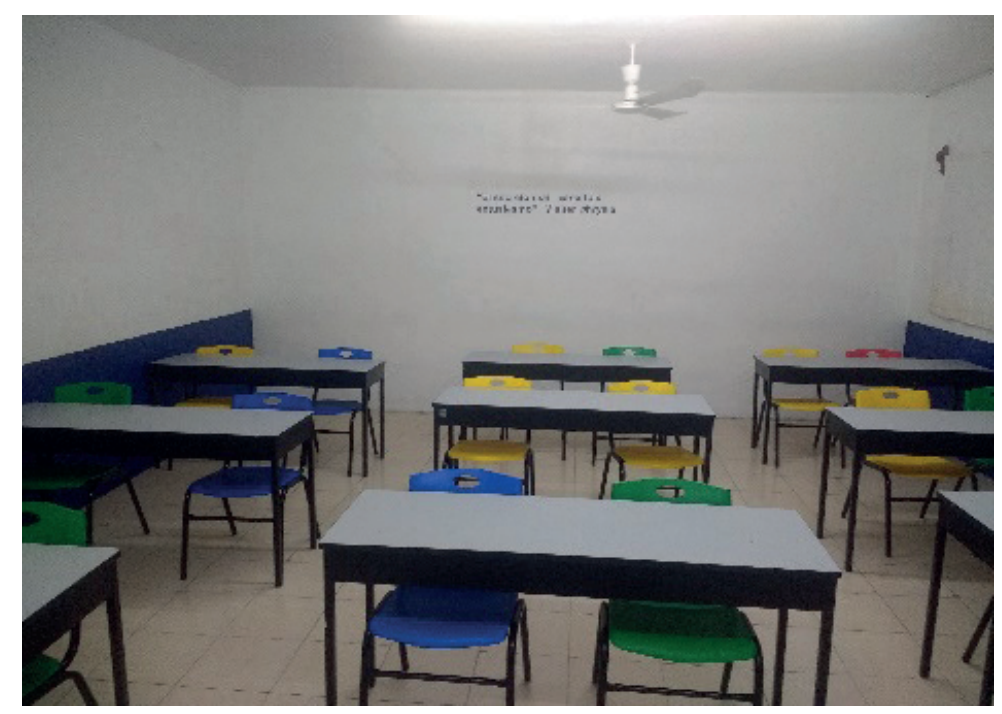

Figural.11. Propia, aula juicios orales

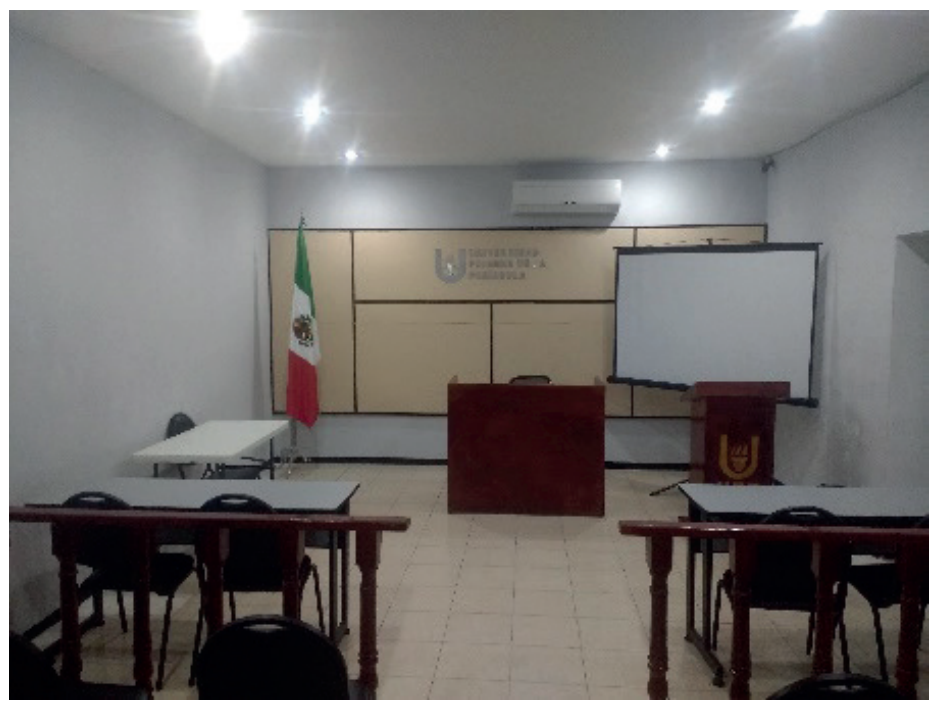

Figuras 1.12, 1.13. Propias, talleres de alimentos y bebidas.
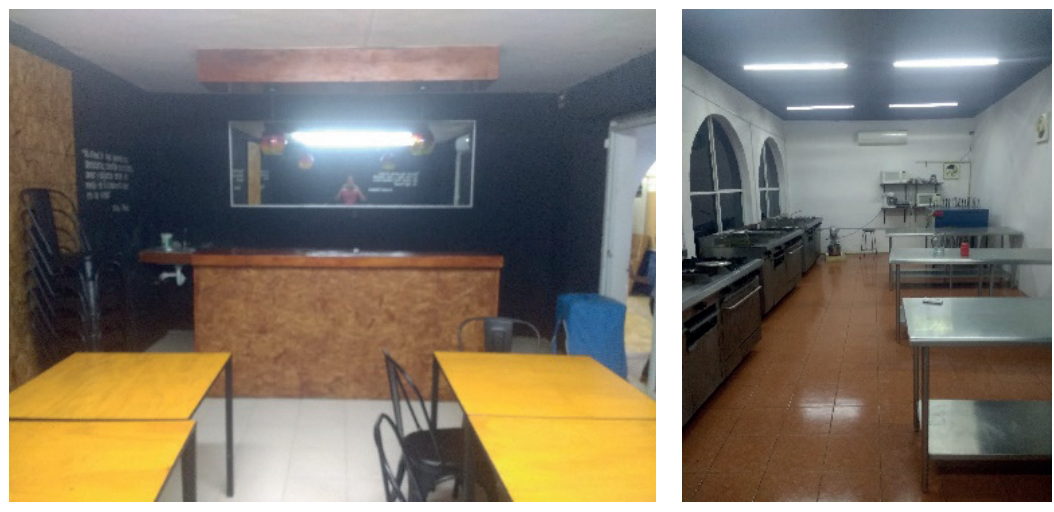
Figura 1.14. Propia, edificio de Odontología.

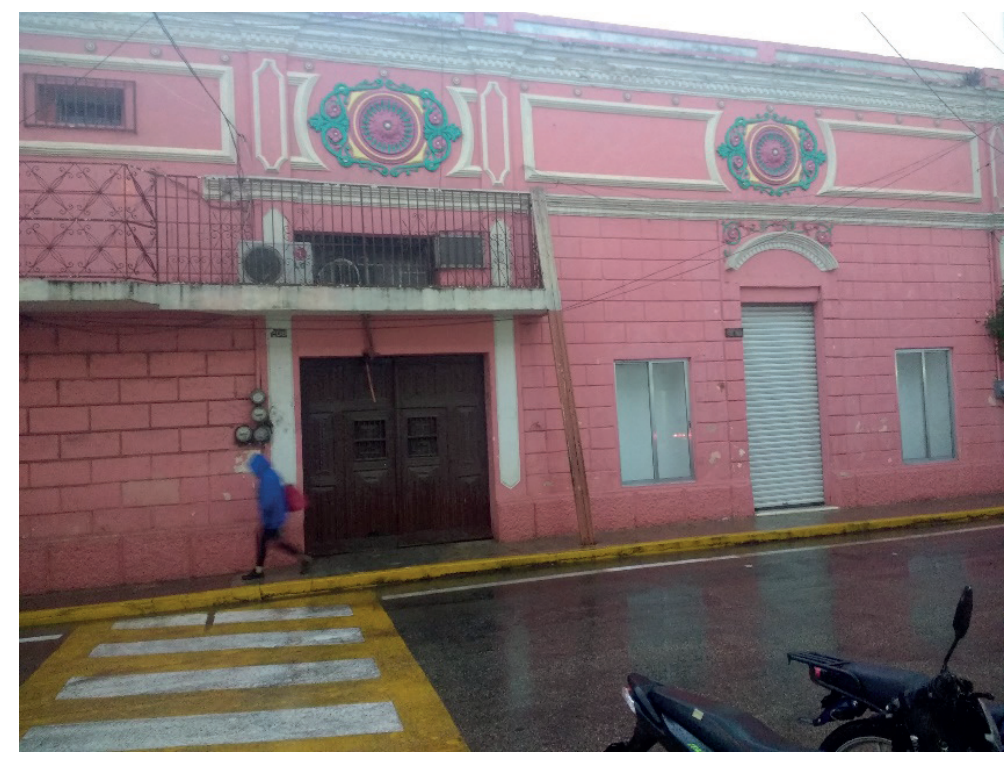

El organigrama de Campus Tekax se muestra en la figura 1.15 a continuación.

Figura 1.15. Elaboración propia con datos proporcionados $p$ or la Jefatura de Servicios Escolares del Campus

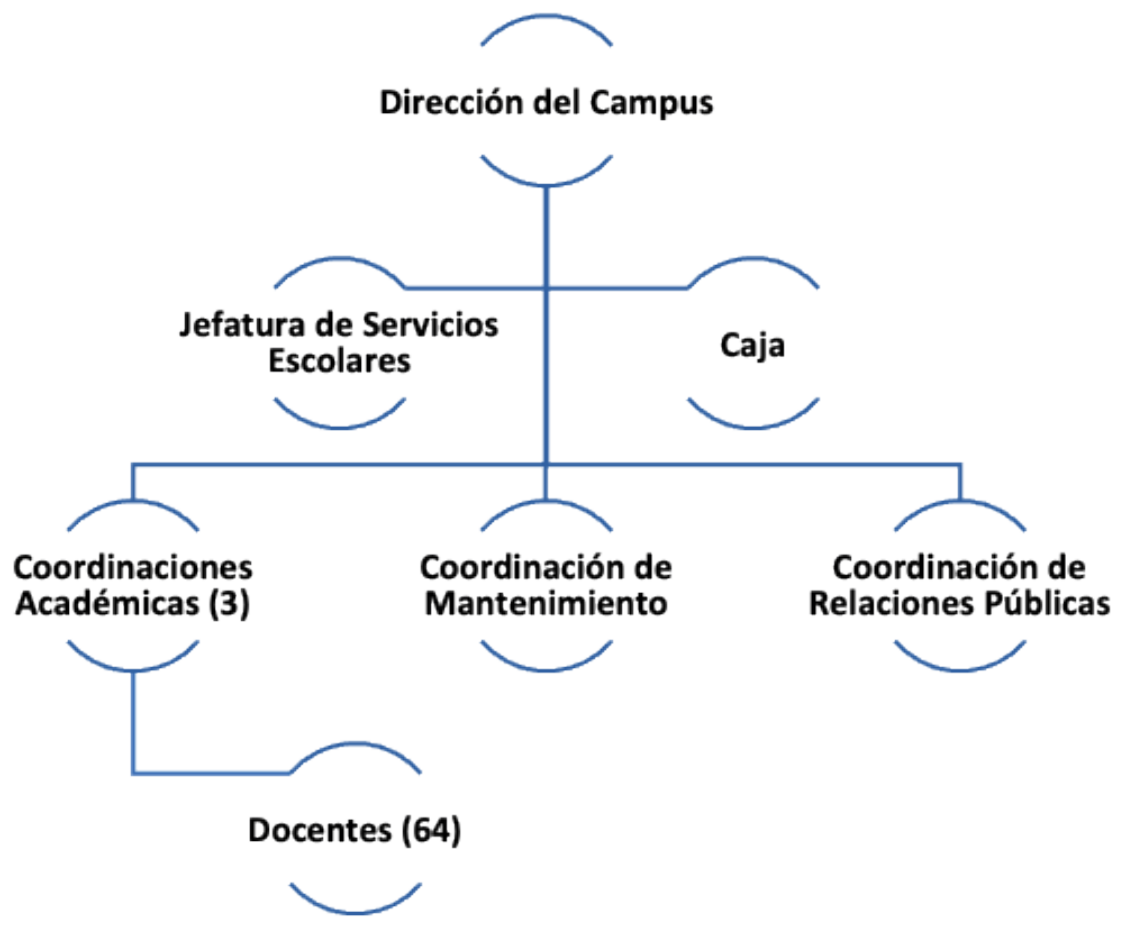

En Yucatán la Institución alberga a $38.05 \%$ de los alumnos son hombres y el 1,453 alumnos (ANUIES, 2019), "339 alum$61.95 \%$ son mujeres, la comunidad univernos son de Campus Tekax, de los cuales el sitaria está compuesta por alumnos prove- 
nientes de las localidades de Tekax de Álvaro Obregón, Akil, Oxkutzkab, Tzucacab, Peto, Tixmeuac, Maní, Kancab, Ticul, Tahdziú, Tabasco, Mérida y Cozumel. El claustro docente está conformado por 64 profesores, quienes cuentan con licenciatura, pero ninguno ha realizado una maestría, sin embargo, cabe señalar que 15 de ellos están cursando estudios de posgrado dentro de la misma institución; el claustro docente está conformado por 25 hombres, quienes representan el $39 \%$ y 39 mujeres, quienes representan el $61 \%$. Los docentes de Campus Tekax son de diferentes ciudades del Estado, la distribución de docentes por lugar de procedencia es: 29 docentes de Tekax de Álvaro Obregón,
11 docentes de Oxkutzkab, 9 docentes de Mérida, 7 docentes de Tzucacab, 5 de Akil, 2 de Mani y 1 de Peto. Del $100 \%$ de los docentes de Campus Tekax, el 12 \% (8 docentes) son de tiempo completo, mientras que el resto, 88 \% (56 docentes) están contratados por honorarios bajo la modalidad de asignación de horas cuatrimestrales, no hay docentes de medio tiempo" (Jefatura de Servicios Escolares del Campus, comunicación directa, 14 de noviembre de 2019).

La oferta educativa en Campus Tekax, así como, la distribución de la matrícula por cada carrera se encuentra descrita en la tabla 1.5 a continuación.

Tabla 1.5. Elaboración propia con datos obtenidos de la Jefatura de Servicios Escolares de la UPP Campus Tekax, 2019

\begin{tabular}{|c|c|c|c|}
\hline Psicología & Pedagogía & Psicopedagogía & Odontología \\
\hline 24 & 25 & 68 & 41 \\
$7.07 \%$ & $7.37 \%$ & $20.05 \%$ & $12.09 \%$ \\
\hline Nutrición & Gastronomía & Derecho & Derecho Ejecutivo \\
\hline 11 & 37 & 39 & 66 \\
$3.24 \%$ & $10.91 \%$ & $11.50 \%$ & $19.46 \%$ \\
\hline Administración & Contaduría Pública & Turismo & Enfermería \\
\hline 0 & 0 & 0 & 28 \\
$0 \%$ & $0 \%$ & $0 \%$ & $8.25 \%$ \\
\hline
\end{tabular}

"En la actualidad, el campus ha dado salida a tres generaciones (2016, 2017 y 2018), con una eficiencia terminal del $75 \%$; las opciones de titulación que los alumnos tienen son: por examen profesional y por medio de la incorporación a los posgrados que la Institución ofrece" (Jefatura de Servicios Escolares, comunicación directa, 14 de noviembre de 2019).

\section{La Directora}

Por cuestiones de confidencialidad, para resguardar la integridad de quien permite llevar a cabo este caso de estudio, se decidió utilizar el sustantivo común de 'La Directora', con quien se tuvo contacto presencial por primera vez el 04 de octubre de 2019, concretando una cita para el día 14 de noviembre de 2019.

La Directora es una mujer de 36 años, madre de 3 hijos (2 niños y una niña en edad infantil), dirige el Campus Tekax desde hace poco más de un año, es egresada de la Escuela Normal Superior. Titulada en el año 2006, cuenta con una experiencia profesional de 15 años, de los cuales, 15 años han sido como docente, y 3 años como parte del personal administrativo, como directora de un centro educativo es su primera experiencia; por tanto, su conocimiento a nivel ejecutivo es del tiempo que lleva como directora 
del Campus. Tiene la fortuna de contar con la presencia de sus padres, de su núcleo familiar es la hermana de en medio de un total de 9 hermanos, entre hombres y mujeres. Físicamente, La Directora es una mujer de estatura media-alta, complexión media, tez color blanca, cabello corto, castaño oscuro y ondulado, ojos color aceituna. Su semblante es enigmático porque se muestra seria, pero esboza una sonrisa que resulta difícil descifrar, su atuendo, cuando no utiliza el uniforme de la institución es sobrio, con vivos típicos de la ropa de la región, cómodo y funcional. Su trato es cordial pero directo, siempre manteniendo contacto visual y dando a entender (sin expresarlo verbalmente, que tiene el control de la situación y que está en su territorio), lo que la proyecta como una mujer segura de sí misma, su tono de voz es grave, impone respeto, ya que es alto sin necesidad de subir la voz, su dicción es clara, al igual que la exposición de sus ideas, su lenguaje corporal es congruente con sus palabras. A priori, con base en este primer contacto y a los estilos gerenciales propuestos por Hoy, W. y Miskel, C. (2012), parece ser, que La Directora ostenta un estilo gerencial transaccional.

\section{Metodología}

El caso de estudio, utilizó un método cualitativo, naturalista vivencial en el que se convive de primera mano con los actores clave y con la comunidad universitaria en su ambiente natural para generar confianza entre el investigador y el grupo de estudio para poder llevar a cabo una investigación de campo por medio de: observaciones no participativas del contexto del campus y desu dinámica social; entrevistas semiestructuradas con actores clave como La Directora, las coordinadoras Académicas, la Jefatura de Servicios Escolares; así como, grupos de enfoque con alumnos de diferentes cuatri- mestres de diferentes licenciaturas. Con lo que se da comprensión de la realidad social (Lincoln, Y. y Guba, E., 1985). El proceso de investigación de campo, tuvo una duración de 2 meses y medio (octubre, noviembre y parte de diciembre de 2019); no obstante, las intervenciones en el Campus estuvieron delimitadas y limitadas en gran medida por la agenda de La Directora, lo que derivó en un proceso de investigación de campo efectiva de 100 horas (12:30 horas semanales).

La recolección de datos se llevó a cabo por medio de técnicas de observación no participativa (acompañamiento con La Directora, observación de procesos administrativos y de enseñanza aprendizaje tanto de alumnos como de docentes) con registro en un diario de campo, entrevistas individuales semiestructuradas con La Directora, 2 coordinadoras académicas, 1 entrevista sin estructura con la jefa de servicios escolares, así como, grupos de enfoque con docentes y alumnos. A partir de la recolección de los datos, se llevó a cabo un análisis de contenido, triangulando los datos para establecer una relación entre lo descubierto y las teorías que dan sustento a la interpretación.

\section{Consideraciones sobre el método}

A lo largo del proceso de investigación, se vivieron cuatro momentos en los que se pudo llevar a cabo la recolección de datos que fueron dando forma al reporte final, y se dieron de la siguiente manera.

\section{Primer momento}

Se dio de manera natural y representó el proceso de observación no participativa en la comunidad en donde se encuentra el campus, lo que permitió hacer un registro (escrito en el diario de investigación y fotográfico) del sitio, para posteriormente analizar el entorno del centro educativo. 


\section{Segundo momento}

Se desarrolló durante el proceso de observación no participativa de la rutina de trabajo de La Directora, momento en el que se pudo la que se pudo notar la manera como interactuaba con su equipo de trabajo, el tipo de relación que había establecidocon ellos y con la comunidad universitaria en general, así como, del acontecer cotidiano durante su horario de trabajo. De lo cual también se tomó registro escrito en el diario de investigación.

\section{Tercer momento}

Ocurrió durante las entrevistas individuales semiestructuradas documentadas en audio con La Directora, las coordinadoras Académicas y la jefa de Servicios Escolares, información que sirvió, por una parte, para conocer la autopercepción de la gestión y el estilo de liderazgo de La Directora, y por otra parte, para identificar el grado de influencia que La Directora ejercía en su equipo de trabajo; así como, el sentido de pertenencia institucional que tienen y en qué manera La Directora ha contribuido para que así sea.

\section{Cuarto momento}

Este se dio durante los grupos de enfoque practicados a alumnos y docentes, los cuales están documentados en video y audio, estos grupos de enfoque sirvieron para entender la percepción que tanto alumnos como docentes tienen sobre la gestión y liderazgo de La Directora, y el sentido de pertenencia, orgullo institucional que tiene la comunidad universitaria hacia la institución.

\section{Análisis de datos}

Para la interpretación de los datos se utilizó un diagrama de afinidad que permitió identificar una serie de cuestiones críticas, mismas que fueron aterrizadas en un diagrama de Venn, que ayuda a comprender mejor los fenómenos sociales que ocurren en el Campus donde se llevó a cabo el estudio. Las cuestiones críticas que sirvieron como base para dar respuesta a las preguntas de investigación: ¿Qué tanto el liderazgo y la gestión administrativa ejercidos por La Directora están influyendo positiva o negativamente en las coordinaciones a su cargo?, ¿qué tanto el liderazgo y la gestión administrativa ejercidos por La Directora están logrando que la filosofía institucional se interiorice en la comunidad universitaria? se muestran en la figura 1.16.

\section{Resultados}

¿Qué tanto el liderazgo y la gestión administrativa ejercidos por La Directora están influyendo positiva o negativamente en las coordinaciones a su cargo?

Las entrevistas realizadas a la directora del Campus, a sus coordinadoras Académicas y a la jefa de Servicios Escolares, dejan ver que tiene el control de las operaciones del campus, nada de lo que ahí sucede pasa desapercibido, y esto es posible, gracias a que prácticamente es omnipresente en el ; es decir, además de los rondines que suele dar prácticamente a diario por las instalaciones del Campus, lo que le permite estar enterada de primera mano sobre el clima institucional o de algún otro suceso que se pueda dar mientras ejecuta esos rondines. La Directora ha sabido tejer una red de comunicación entre su personal operativo, académico y administrativo, que le permite enterarse de prácticamente cualquier cosa que esté sucediendo en el campus. Este tipo de liderazgo sistémico como lo denomina Aldana (2019), le ha sido muy útil para conocer situaciones que en su momento podrían escalar a problemas, si no fuesen detectadas a tiempo. Por otro parte, gracias al ejemplo de La Directora en su actuar diario como directiva transformacional, como lo asegura 
Anderson (2017), logra contagiar de actitud positiva a su equipo de trabajo cercano, para que traten de proyectar lo mismo hacia el resto de la estructura con una fuerte orientación a resultados y al servicio, como también lo asegura Afshari (2011).

la base para lograr que la misión y la visión de la institución se cumplan es el personal tanto administrativo quienes se encargan de dar servicio a los alumnos como a docentes. Y desde luego el personal docente, quienes son clave para que los alumnos se conviertan en lo que la misión manifiesta y con ello se logré la visión de la Universidad. (D. de Campus Tekax, comunicación personal, 12 de marzo de 2020).

la Visión Institucional es el gran objetivo a ser cubierto por todos nosotros, nuestro trabajo se enfoca para lograr que los docentes tengan todas las herramientas materiales y de capacidades para que puedan ejecutar su trabajo de la mejor manera posible y con ello se logre que la Institución sea reconocida por formar seres humanos capaces de contribuir al bienestar económico y social del lugar en donde se encuentren gracias a la aplicación de sus conocimientos y capacidades desarrolladas durante su formación universitaria. (C. Académica de las Licenciatura en Psicología y Pedagogía, comunicación personal, 12 de marzo de 2020).

uno de los valores que la institución aprecia es la puntualidad, aquí se tiene la filosofía de que la puntualidad significa estar $10 \mathrm{mi}$ nutos antes de la hora de entrada y salir a la hora que nuestro horario dicta, de igual manera la buena actitud ante la gente, el siempre recibir a quien nos visite con una sonrisa y estar dispuestos a dar soluciones, el compromiso y la responsabilidad son la base que ayuda a ejercer mi liderazgo hacia mis docentes y alumnos de mis academia. (Coordinación de las licenciaturas de Derecho y Enfermería, comunicación directa, 21 de noviembre de 2019).

durante el proceso de selección de personal, no tenía una idea clara de lo que ser coordinador significaba, de hecho, yo venía buscando otra vacante, la de caja. Sin embargo, quien me entrevistó me comentó que mi perfil se adecuaba mejor a la vacante de coordinadora académica y me preguntó si estaba interesada, a lo cual accedí. No pensé que fuera a ser seleccionada, pero resultó que fui pasando los filtros hasta ser contratada, sin experiencia administrativa y menos aún como coordinadora académica, no me sentía del todo cómoda, de hecho fue un reto para mí, adecuarme a los procedimientos, sin embargo, gracias a la capacitación que se me brindó desde que ingresé a la institución, me he dado cuenta que el trabajo, funcionalmente es fácil y que el verdadero desafío está en la dinámica social que vivimos día a día. (Coordinación Académica de las licenciaturas de Gastronomía y Nutrición, comunicación directa, 21 de noviembre de 2019).

\section{¿Qué tanto el liderazgo y la gestión administrativa ejercidos por La Directora han logrado que la filosofía institucional se interiorice en la comunidad universitaria?}

El proceso de investigación de campo llevado a cabo con los alumnos resultó interesante, mediante los grupos de enfoque ejecutados, se pudo identificar que los alumnos de la Institución se sienten honrados de pertenecer a la Universidad, esto gracias a que la Institución se muestra congruente entre la filosofía que profesa y sus acciones, como lo aseveran Cyert, y March (1963) y Olcum y Fayda (2015). Los alumnos se identifican con la filosofía institucional, agradecen las oportunidades y ayuda que reciben de La Directora y de su equipo de trabajo para la solución de problemas, sobre todo, de índole económico, ejerciendo un liderazgo creativo y proactivo como lo mencionan Burquei (2018). De igual manera, se descubrió, como lo afirman Haveman y Smeeding (2006) los alumnos sienten un profundo respeto hacia sus maestros y los consideran personas preparadas, profesionales y comprometidos con la enseñanza, debido al rol que juegan no 
nada más como docentes, sino, como mentores y consejeros cuando asi es requerido. Los alumnos sienten que La Directora es distante con ellos, que es difícil acceder a ella, sienten que no trabaja a la par de sus subordinados y que nada más hace acto de presencia en los momentos clave de las actividades extracurriculares o en los eventos que el campus llega a organizar, la perciben como una figura autoritaria, pero, todos coinciden que les ha resuelto problemas clave que les han permitido continuar con sus estudios sin afectación alguna, ajustando su estilo de liderazgo, mostrando un liderazgo humanizado, como lo define Bennis y Nanus (1985).

todos los esfuerzos de la Institución están organizados para el logro de la Visión Institucional, misma que tendrá que ser una realidad en el año 2022 (D. de Campus Tekax, comunicación personal, 12 de marzo de 2020).

nuestros docentes son la clave para que los alumnos asuman nuestra filosofía, para tal motivo, se les brindan capacitaciones cada cuatrimestre en diversos temas y uno de los esenciales, es el tema de liderazgo, y el reforzamiento de nuestros valores, misión y visión (D. de Campus Tekax, comunicación personal, 12 de marzo de 2020).

nos sentimos orgullosos de pertenecer a esta institución, los maestros son dedicados, profesionales y muy conocedores de su ramo, la institución fomenta la inclusión educativa de diversas maneras, al dar oportunidad de que personas con discapacidad puedan acceder a la escuela, las instalaciones están adaptadas para que personas con discapacidad puedan transitar por ellas, recientemente dos alumnos discapacitados recibieron su título, uno de ellos era ciego y el otro estaba en silla de ruedas, por otra parte, la escuela tiene diversos programas de becas para que alumnos de escasos recursos puedan estudiar, las becas pueden ir desde un $10 \%$ hasta un $70 \%$, dependiendo del tipo de beca y de la situación de cada alumno, dando preferencia a alumnos de comunidades rurales maya hablantes. Independientemente al plan de becas, cuando nos enfrentamos a alguna situación en la cual no podemos efectuar nuestros pagos en tiempo, siempre hay una repuesta por parte de la Directora para ayudarnos a resolver la problemática y poder seguir estudiando. (Alumnos de diversas carreras y diversos semestres, comunicación directa en grupo de enfoque, 15 de noviembre de 2019)

\section{Conclusiones}

Una institución de educación superior por su complejidad puede tener muchos significados para todos los involucrados en sus procesos como lo indican Lawrence y Lorsch (1967). Con base en lo investigado en el presente caso de estudio, se puede observar que la Universidad que dio las facilidades para llevarlo a cabo tiene presente lo propuesto en los postulados de Sen (1990) y Bimbaum, R. (1988), porque dentro de su visión institucional establecen que la Universidad tendrá que ser una institución reconocida socialmente por desarrollar capital humano integro e integral, capaz de contribuir al desarrollo económico y social del País (UPP, 2019), lo que también está apoyado en las teorías económicas propuestas por Cypher y Dietz (2009), así como, por las teorías de relaciones intergrupales desarrolladas por Alderfer y Clayton (1980).

Para lograr lo anterior en una institución de educación superior, según Bolman y Deal (1991), se requiere diseñar y gestionar un modelo administrativo que contemple cuatro marcos organizacionales (marco estructural, marco de recursos humanos, marco político y marco simbólico), las evidencias mostradas durante la investigación de campo mostraron que el campus estudiado cuenta con tres de los cuatro marcos antes mencionados el estructural con un plan de desarrollo institucional que contiene el plan estratégico de la institución, planes y programas de estudio con sus respectivos re- 
gistros de validez oficial, manuales de administración y operación, formatos para dejar evidencias cuando así se requiera; el marco de recursos humanos se puede apreciar con facilidad, tiene un proceso de reclutamiento y selección bien definido, cuenta con un programa de capacitación y entrenamiento para docentes y personal administrativo encaminado a mejorar su desempeño y actitudes; el otro marco organizacional que se puede identificar, es el simbólico, desde que uno entra a las instalaciones del campus es fácil visualizar frases motivadoras de personajes famosos e ilustres, todas los fondos de pantalla de las computadoras tienen el número 2022, cuyo significado es el logro de la visión institucional; el personal del Campus y los alumnos tienen muy presente lo que la filosofía institucional significa y en su gran mayoría comparten los valores y la misión, con los que se sienten comprometidos para lograr la visión institucional como lo manifiestan Blanchard y O'Connor (2005). En el campus no hay evidencias de que el marco organizacional político se haya desarrollado, probablemente por el modelo de administración centralizado de toma de decisiones que maneja la Institución, que impide la mejora en las condiciones comerciales con actores clave, como lo asegura Tallerico (2007).

Para el logro de la Visión, según Hoy y Miskel (2012), se requiere de un liderazgo que cuente con características transformacionales y transaccionales como: orientación a la solución de problemas, el empoderamiento de su equipo de trabajo; generador de clima propicio para dar resultados; motivación de su equipo de trabajo con base en desafíos y premios; empatía con su equipo de trabajo; centralización de la toma de decisiones; así como, el seguimiento al cumplimiento de las encomiendas. De tal suerte que después de haber hecho la recolección de datos se puede observar que La Directora posee las siguientes cualidades de liderazgo, como lo muestra la tabla 1.6.

Tabla 1.6. Características de liderazgo de La Directora

\begin{tabular}{|l|l|}
\hline \multicolumn{1}{|c|}{ Liderazgo transaccional } & \multicolumn{1}{c|}{ Liderazgo transformacional } \\
\hline Orientada a la tarea & Fuerte orientación hacia el servicio \\
Orienta a su equipo de trabajo para que las cosas se & Fuerte orientación al logro \\
hagan & Genera un clima organizacional de confianza, respeto y \\
Alienta la participación, pero la decisión es de ella & compromiso \\
Firmeza para corregir y en la toma de decisiones & Empodera al personal a su cargo para que puedan resol- \\
& ver problemas \\
\hline
\end{tabular}

Fuente: elaboración propia con datos de (diario de investigación), (entrevistas individuales a actores clave), (grupos de enfoque practicados a docentes y alumnos) (Hoy y Miskel, C. 2012)

Para el poco tiempo que La Directora lleva al frente del campus, gracias su liderazgo y creatividad soluciona problemas, tal cual lo sugiere Afshari (2011), puesto que a pesar de tener un campo de acción limitado en la toma de decisiones, ha logrado alinear la operación del campus a las expectativas que las autoridades de la institución tienen para lograr el cumplimiento de la Visión, así como, la aceptación y arraigo del campus en la comunidad, como lo establece Kanter (1977); de igual manera, ha logrado influir de manera positiva en sus subordinados directos con la filosofía institucional, pero también con su propia filosofía personal, que es muy similar a la institucional. Por medio del ejemplo ha logrado que su equipo de trabajo sea comprometido y responsable con las encomiendas que se les asignan e incluso, la ven como un modelo a seguir como lo su- 
giere Kotter (1982), sin embargo, ese liderazgo transformacional, que efectivamente es apreciado por sus subordinados directos, no es percibido del todo entre la comunidad de docentes, ni tampoco la estudiantil, quienes la perciben como una lideresa transaccional. Pero a pesar de ello, los alumnos aceptan que La Directora es buena persona y que cuando han requerido ayuda de ella, para cuestiones importantes, la han recibido. Los alumnos no se dan cuenta de que ese orgullo institucional y de pertenencia que sienten por ser parte de la comunidad estudiantil de la Universidad, en gran medida, es gracias a su gestión y liderazgo, quien en sus palabras menciona:

mi equipo de trabajo y yo estamos aquí para satisfacer cualquier requerimiento que los alumnos y sus padres puedan tener. (Directora de Campus Tekax, comunicación directa, 14 de noviembre de 2019).

De igual manera, los alumnos no alcanzan a entender que la función de un directivo, es lo que La Directora ejecuta con efectividad, es decir, planear, estructurar, guiar y controlar (Robins y Coulter, 2005) las operaciones del Campus, dejando que su equipo de trabajo ejecute dichas operaciones, demostrando así un liderazgo situacional, acorde a las circunstancias, como lo menciona Badillo (2015), por ello, los comentarios de los alumnos sobre falta de compromiso con respecto de la ejecución de los eventos en el Campus y fuera de él están fuera de contexto.

\section{Referencias}

Afshari, M. (2011). Leadership \& Creativity. Australian Journal of Basic and Applied Sciences, 5(10), 1591-1594. Recuperado de http:// www.academia.edu/1327547/Leadership_ and_Creativity

Aldana, J. (2019). Liderazgo sistémico en las competencias gerenciales docentes universitarias. CIENCIAMATRIA, 5(8). ecupe- rado de http://www.cienciamatriarevista. org.ve/index.php/cm/article/view/87

Alderfer, C. y Clayton, P. (1980). Studying Intergroup Relations Embedded in Organizations. Yale University. School of Organization and Management.

Anderson, M. (2017). Transformational Leadership in Education: A review of existing literature. International Social Science Review, 93(1), 1-13. Recuperado de https://digitalcommons.northgeorgia.edu/cgi/viewcontent.cgi? article $=1213 \&$ context $=$ issr

ANUIES (2019). Anuario estadístico de educación superior 2017-2018. Recuperado de http:// www.anuies.mx/gestor/data/personal/ anuies05/anuario/ANUARIO_EDUCACION_ SUPERIOR-LICENCIATURA_2018-2019.zip

Badillo, R. (2015). Liderazgo de los Rectores Frente a la "Tercera Misión" de la Universidad. Revista Mexicana de Investigación Educativa., 20(65), 393-417. Recuperado de http://www.google.com.mx/url?sa=t\&rct $=j \& q=\&$ esrc $=s \&$ source $=$ web\&cd $=1 \& c a$ $d=$ rja\&uact $=8 \&$ ved $=2$ ahUKEwilt_edOP_ dAhVIMqwKHdT2B_KQFjAAegQICRAC \&url=http\%3A\%2F\%2Fwww.redalyc. org\%2Fpdf\%2F140\%2F14035408004.pd f\&usg=AOvVaw2jrSOKCpLEsNVASBVLjoNU

Bennis, W. \& Nanus, B. (1985). Leaders: Strategies for Taking Charge (2. ${ }^{\text {a }}$ ed.). Boston: HarperBusinees.

Bimbaum, R. (1988). How Colleges Work: The Cybernetics of Academic Organization and Leadership.: Jossey-Bass.

Blanchard, K. y O'Connor, M. (2005). Administración por valores: cómo lograr el éxito organizacional y personal mediante el compromiso con una misión y unos valores compartidos. Ed. Norma

Bolman, L. y Deal, T. (1991). Reframing Organizations. Jossey-Bass Publishers.

Burquei, N. (2018). Howareuniversitiescreatingthe leaders they need? Univesity World News. Recuperado de https://www.university worldnews.com/post.php?story=20180 220134208899

Cyert, R. y March, J. (1963). Behavioral Theory of the Firm. Englewood Cliffs. Prentice Hall. 
Cypher, J. y Dietz, J. (2009). The Process odf Economic Development (3. a ed.). Routledge Taylos \& Francis Group.

Gobierno Estatal del Estado de Yucatán, (2019a). Yucatán. Recuperado de http://www.yucatan.gob.mx/estado/

Gobierno Estatal del Estado de Yucatán, (2019b). Medio físico. Recuperado de http://sds. yucatan.gob.mx/biodiversidad-yucatan/ libro-biodiversidad-yucatan.php

Gobierno Estatal del Estado de Yucatán, (2019c), Perfil demográfico. Recuperado de http:// www.yucatan.gob. $m x / ? p=$ perfil_demografico

Haveman, R. y Smeeding, T. (2006). The Role of Higher Education in Social Mobility. The Future of Children, 16(2), 125-150. Recuperado de https://www.researchgate.net/ publication/6757930_The_Role_of_Higher_ Education_in_Social_Mobility

Hoy, W. y Miskel, C. (2012). Educational administration theory, research, and practice. Random House.

INEGI. (2017). Anuario estadístico y geográfico de Yucatán 2017. Recuperado de https:// www.datatur.sectur.gob.mx/ITxEF_Docs/ YUC_ANUARIO_PDF.pdf

INEE, (2019). Banco de indicadores educativos. Recuperado de https://www.inee.edu.mx/ wp-content/uploads/2019/09/2018_Ciclo2017-2018.pdf

Kanter, R. (1977). Management-Oriented Management Information Systems. Prentice Hall.

Kotter, J. (1982). The General Managers. Free Press.

Lawrence, P. y Lorsch, J. (1967). Differentiation and Integration in Complex Organizations. Administrative Science Quarterly, 12(1), 1-30. doi:https://doi.org/10.2307/2391211.

Lincoln, Y. y Guba, E. (1985). Naturalistic Inquiry. London, England, SAGE Publications. Recuperado de https://books.google.com. $\mathrm{mx} /$ books? $\mathrm{id}=20 \mathrm{~A} 9 \mathrm{aWINeooC} \&$ printsec $=f$ rontcover $\&$ hl=es\&source=gbs_ge_summa $r y_{-} r \& c a d=0 \# v=$ onepage $\& q \& f=$ false

Mérida de Yucatán. (2012). El origen del nombre Yucatán. Recuperado de https://www.meridadeyucatan.com/origen-del-nombreyucatan/
Olcum, M. y Fayda, F. (2015). An analysis of academic leadership behavior from the perspective of transformational leaership. Procedio Social and Behavioral Sciences (207), 519-527. Recuperado de https:// www.sciencedirect.com/science/article/ pii/S1877042815052556

Robins, S. y Coulter, M. (2005). Administración. Pearson Education.

Sen, A. (1990, December 20). More than 100 million women are missing. (N. Y. Books, Ed.) New York. Recueorado de https://www. nybooks.com/articles/1990/12/20/morethan-100-million-women-are-missing/

Tallerico, M. (2007). Reframing the Education Gap in the Ithaca City School District, Barry Derfel. Manuscrito Inédito. Binghamton.

UPP. (2018). UPP. Retrieved from Historia: http:// www.universidadupp.edu.mx/nosotrosu $r l$ ? sa $=t \& r c t=j \& q=\&$ esrc $=s \&$ source $=$ web $\& c d=1 \& c a d=r j a \&$ uact $=8 \&$ ved $=2$ ahUKEwi Ir_edOP_dAhVIMqwKHdT2B_kQFjAAegQICR AC\&url=http\%3A\%2F\%2Fwww.redalyc. org\%2Fpdf\%2F140\%2F14035408004.pd f\&usg=AOvVaw2jrSOKCpLEsNVASBVLjoNU

Bennis, W. \& Nanus, B. (1985). Leaders: Strategies for Taking Charge (2.. ed.). Boston: HarperBusinees.

Bimbaum, R. (1988). How Colleges Work: The Cybernetics of Academic Organization and Leadership.: Jossey-Bass.

Blanchard, K. y O'Connor, M. (2005). Administración por valores: cómo lograr el éxito organizacional y personal mediante el compromiso con una misión y unos valores compartidos. Ed. Norma

Bolman, L. y Deal, T. (1991). Reframing Organizations. Jossey-Bass Publishers.

Burquei, N. (2018). How are universities creating the leaders they need? Univesity World News. Recuperado de https:// www.universityworldnews.com/post. php?story=20180220134208899

Cyert, R. y March, J. (1963). Behavioral Theory of the Firm. Englewood Cliffs. Prentice Hall.

Cypher, J. y Dietz, J. (2009). The Process odf Economic Development (3.. ed.). Routledge Taylos \& Francis Group. 
Gobierno Estatal del Estado de Yucatán, (2019a). Yucatán. Recuperado de http://www.yucatan.gob.mx/estado/

Gobierno Estatal del Estado de Yucatán, (2019b). Medio físico. Recuperado de http://sds. yucatan.gob.mx/biodiversidad-yucatan/ libro-biodiversidad-yucatan.php

Gobierno Estatal del Estado de Yucatán, (2019c), Perfil demográfico. Recuperado de http:// www.yucatan.gob.mx/?p=perfil_demografico

Haveman, R. y Smeeding, T. (2006). The Role of Higher Education in Social Mobility. The Future of Children, 16(2), 125-150. Recuperado de https://www.researchgate.net/ publication/6757930_The_Role_of_Higher_ Education_in_Social_Mobility

Hoy, W. y Miskel, C. (2012). Educational administration theory, research, and practice. Random House.

INEGI. (2017). Anuario estadístico y geográfico de Yucatán 2017. Recuperado de https:// www.datatur.sectur.gob.mx/ITxEF_Docs/ YUC_ANUARIO_PDF.pdf

INEE, (2019). Banco de indicadores educativos. Recuperado de https://www.inee.edu.mx/ wp-content/uploads/2019/09/2018_Ciclo2017-2018.pdf

Kanter, R. (1977). Management-Oriented Management Information Systems. Prentice Hall.

Kotter, J. (1982). The General Managers. Free Press. Lawrence, P. y Lorsch, J. (1967). Differentiation and Integration in Complex Organizations. $A d$ - ministrative Science Quarterly, 12(1), 1-30. doi:https://doi.org/10.2307/2391211.

Lincoln, Y. y Guba, E. (1985). Naturalistic Inquiry. London, England, SAGE Publications. Recuperado de https://books.google.com. $\mathrm{mx} /$ books? $\mathrm{id}=20 \mathrm{~A} 9 \mathrm{aW} I$ NeooC $\&$ printsec $=f$ rontcover\&hl=es\&source $=$ gbs_ge_summa $r y \_r \& c a d=0 \# v=$ onepage $\& q \& f=$ false

Mérida de Yucatán. (2012). El origen del nombre Yucatán. Recuperado de https://www.meridadeyucatan.com/origen-del-nombreyucatan/

Olcum, M. y Fayda, F. (2015). An analysis of academic leadership behavior from the perspective of transformational leaership. Procedio Social and Behavioral Sciences (207), 519-527. Recuperado de https:// www.sciencedirect.com/science/article/ pii/S1877042815052556

Robins, S. y Coulter, M. (2005). Administración. Pearson Education.

Sen, A. (1990, December 20). More than 100 million women are missing. (N. Y. Books, Ed.) New York. Recueorado de https://www. nybooks.com/articles/1990/12/20/morethan-100-million-women-are-missing/

Tallerico, M. (2007). Reframing the Education Gap in the Ithaca City School District, Barry Derfel. Manuscrito Inédito. Binghamton.

UPP. (2018). UPP. Retrieved from Historia: http:// www.universidadupp.edu.mx/nosotros 